Contemporary Research in Education and English Language Teaching

ISSN: 2641-0230

Vol. 1, No. 4, pp. 45-56

2019

Publisher: Learning Gate

DOI: $10.33094 / 26410230.2019 .14 .45 .56$

(C) 2019 by the authors; licensee Learning Gate

\title{
Effects of Task Familiarity and Task Repetition on Iranian EFL Learners' Engagement in L2 Oral Performance
}

\author{
Mahsa Nazemi \\ Department of English, Isfahan (Khorasgan) Branch, Islamic Azad University, Isfahan, Iran \\ Ehsan Rezvani \\ Department of English, Isfahan (Khorasgan) Branch, Islamic Azad University, Isfahan, Iran
}

Received: 14 October 2019; Revised: 11 November 2019; Accepted: 29 November 2019; Published: 12 December 2019

\begin{abstract}
The present study aimed at investigating the effects of content familiarity and task repetition on Iranian EFL learners' engagement in L2 oral performance. To this end, 44 intermediate EFL learners (17 males and 27 females) from Nahal, Nik, Rastak and Noyan English institutes in Isfahan, Iran, whose age range from 16 to 25, were selected through Oxford Placement Test (OPT). To collect the data, one familiar narrative task (events in Iran) and one unfamiliar task (events in China) were selected for the participants to narrate each one two times. After this phase, a stimulated recall interview was conducted with all the selected participants to capture their inner thoughts about speech production and affective responses to content familiarity and task repetition. After the data collection, the data were analyzed to compare the two familiar and unfamiliar topics to explore the effect of familiarity on learners' engagement in Oral performance, and also to find the effects of task repetition in both familiar and unfamiliar tasks. In addition, he data obtained from the interview were analyzed through content analysis. The results of this study revealed that there was a significant difference between the level of behavioral and cognitive engagement between the familiar and unfamiliar task and also between the first and the second performances of each. Moreover, potential interaction effect was spotted between content familiarity and task repetition in terms of the four indicators.
\end{abstract}

Keywords: Task familiarity, Task engagement, Task repetition, L2 oral performance.

\section{Introduction}

Over the last three decades task-based approaches to second language (L2) instruction have become increasingly popular, but research has focused primarily on the effects of task design and implementation on language processing during task performance. The role of tasks in improving the quality of learners' engagement in task performance has received relatively little empirical attention. A growing understanding of engagement and its relationship to learning has only recently highlighted in applied linguistics (Christenson, Reschly \& Wylie, 2012).

The complex nature of engagement, as a performance construct, emphasizes the interdependence between the cognitive, the social, and the affective aspects of learners' involvement in language use. This is important because it recognizes the potential contribution of social and affective dimensions of task-based interaction in mediating learners' perceptions and willingness to work hard on a task (e.g. Baralt, Gurzynski-Weiss \& Kim, 2016).

On the other hand, tasks have a primary focus on meaning, induce learners to draw on their linguistic and cognitive resources, and are outcome oriented (Samuda and Bygate, 2005). These qualities have rendered tasks enormously practical instruments for not only teaching and assessing languages, but also for researching language learning processes. In addition, tasks can be performed and enacted in 
a variety of ways using a range of methodological options. Task repetition is another task-based pedagogical procedure which has attracted researchers over the past two decades (Bygate, 1996; Ahmadian \&Tavakoli, 2011). More generally, it is argued that repeating the same (or a slightly altered) task at intervals of one or two weeks, makes learners' attention resources available and could help them direct more cognitive resources towards different dimensions of their L2 performance than they might otherwise do (Samuda \& Bygate, 2005). The present study investigates what makes some tasks essentially more motivating than others. From a practitioner's point of view, this is a crucial aspect of task design and implementation as it relates directly to improved instructional practice and the quality of learners' performance in the classroom.

\section{Literature Review}

In the late 20th century, task-based approach is a revolution in ELT which has been developed based on the concept of tasks. According to Leaver and Willis (2004) "task-based language teaching (TBLT) helps language learners make real efforts to communicate as best as they can in the foreign language which they are learning". Therefore, task-based instruction (TBI) is an approach which focuses on real world language use to serve the purpose of goal-oriented communication.

According to Ellis (2003) "a task is a work plan that requires learners to process language pragmatically in order to achieve an outcome that can be evaluated in terms of whether the correct or appropriate propositional content has been conveyed." Therefore, meaning should be paid close attention and tasks need to be integrated with their own linguistic resources despite the need of choosing particular forms. The purpose of a task should result in language use and lead to the way language is used in a real life and authentic situation. A task, like other language activities, involves productive or receptive, and oral or written skills in diverse cognitive activities.

Research in the field of instructed second language acquisition (SLA) has confirmed the benefits of using pedagogic tasks for interaction-driven language learning (Ellis, 2003, 2012 for a review; Keck et al., 2006). Many of these studies have explored how task design (e.g., task complexity) and task implementation factors such as task planning time, task repetition and task familiarity can affect taskbased interactional features, second language (L2) performance, and/or subsequent learning (e.g., Bygate, 2001; Foster and Skehan, 1996; Philp et al., 2006; Robinson, 2007).

\subsection{Studies on Content Familiarity}

In this study, content familiarity is defined as Carrell's (1987) definition of content schemata, which refers to the knowledge, related to the content domain that learners bring to the reading and listening text or the spoken and written discourse. In literature, while the facilitative role of content familiarity in L2 learners' reading and listening comprehension is well documented (Leeser, 2007; Schmidt-Rinehart, 1994), its positive effects on developing speaking performance have not been explored until recently.

Gilakjani \& Ahmadi (2011) investigated the effect of text familiarity on listening comprehension. The paper emphasized two main issues. Firstly, it investigated the effect of text familiarity on listening comprehension of Iranian EFL learners. Second, it investigated the influence of text familiarity on some aspects of the language. The findings showed that text familiarity has a considerable and significant impact on listening comprehension of Iranian EFL learners.

Hazar \& Rahimpour (2007) examined the impact of topic familiarity on accuracy, complexity, and fluency of L2 oral output. The findings focused on the need to consider topic familiarity as a task feature in syllabus design and materials development and the necessity of considering this task feature for accomplishing accuracy, complexity, or fluency in oral task production.

In another study by Yazdanpanah (2007) significant relationship between text topic familiarity and gender on reading comprehension performance was not found. This researcher not only investigates the interaction of a reading comprehension test with gender in a formal testing context but also the performance of males and females on reading test items with regard to demands on strategy use. His theoretical bases were schema theory and interactive reading. 


\subsection{Task Repetition}

Task repetition involves circling the steps from which learners should take and language learners are asked to repeat the same or slightly reformed task for a week or two (Bygate and Samuda, 2005). Task repetition is often argued as an implementation procedure for oral tasks, as it is commonly believed that learners improve their L2 performance by repeating the same or similar tasks. There are different forms of repetition, such as repeating the same procedure with different content (procedural repetition) and repeating the same task with same content (Ellis, 2009). In this study, task repetition refers to repeating the same task and content.

According to Bygate and Samuda (2005), task repetition is a kind of planning and they claim that repetition has "the potential to lead to integration of knowledge and performance" and it could be regarded as "facilitating changes particularly in the conceptualization and formulation phases of the production process” (Bygate and Samuda, 2005).

\subsubsection{Studies on Task Repetition}

Bozorgian and Kanani (2017) studied the effects of task repetition on accuracy and fluency of EFL learners' speaking skill. The results of their study indicated that learners in the experimental group completed task repetition outperformed better than the other learners in the control group. Moreover, the findings of pre-test and post-test showed that task repetition led to improvement in the intermediate learners ${ }^{\text {ee }}$ accuracy and fluency in speaking skill.

Qui \& Yi Lu (2016) explores the influence of content familiarity and task repetition on English as a foreign language (EFL) learners' engagement in oral performance. Repeating the tasks, however, can negatively influenced behavioral and cognitive engagement, although the participants felt more relaxed and confident. Additionally, the participants were more motivated to repeat unfamiliar topics, although they demonstrated more noticeable declines in their frequency of self-repair (an indicator of cognitive engagement) for these topics.

Birjandi \& Ahangari (2008) explored the effects of task repetition and task type on fluency, accuracy, and complexity of Iranian EFL learners' oral performance. The results revealed that task repetition, and task type, as well as the interaction between these variables resulted in significant differences in subjects' oral discourse in terms of fluency, accuracy, and complexity.

\subsection{Task Engagement}

Task engagement has been much highlighted in recent second language acquisition studies, such as student engagement in corrective feedback (Ellis, 2010). Researchers claim that task engagement drives learning (Philp \& Duchesne, 2016). Despite its potential role in affecting students' task performance; it remains relatively underexplored in research scope of task-based language teaching (TBLT). Teachers may attempt to design and implement various tasks to engage their students.

Engagement is a multidimensional construct. It consists of four dimensions: behavioral, cognitive, affective and social dimensions (Philp \& Duchesne, 2016). Behavioral engagement relates to concentration, attention and effort and is often measured by time on task and participation (Philp \& Duchesne, 2016; Reeve, 2012). In the context of speaking activities, L2 learners' behavioral engagement is often operationalized as time on task, word count (Bygate \& Samuda, 2009) and turn taking. Cognitive engagement involves the mental effort made to achieve target learning outcomes and conceptual understanding (Reeve, 2012). Attention to language in the form of monitoring and selfrepair are considered as cognitive engagement (Wolters \& Taylor, 2012).

Philp and Duchesne (2016), in their study suggest the investigation of exploratory talk and propose elaborative clauses as other possible indicators (Barnes, 2008; Lambert, Philp \& Nakao, 2017; Mercer \& Dawes, 2008). Unlike behavioral and cognitive engagement which can be measured in terms of language use, emotional engagement involves students' affective response to tasks in the classroom. Emotional engagement might thus function as a filter on learners' behavioral and cognitive engagement in L2 use during completing tasks (Lambert et al., 2017). Social engagement reflects the social dimension of 
interaction, such as backchannels and powerful social goals from the sociocultural perspective. Yet, as this study's participants only produce narrative accounts without interacting with others, only the behavioral, cognitive and emotional dimensions of engagement will be examined.

\section{Research Questions}

In this study, the following two research questions were focused on:

1. Does content familiarity affect EFL learners' engagement in L2 oral performance?

2. Does tasks repetition affect EFL learners' engagement in L2 oral performance?

3. What are the potential interaction effects between content familiarity and task-repetition on EFL learners' engagement in L2 oral performance?

\section{Methods}

\subsection{Participants}

A random sampling was employed to select about 60 Iranian intermediate EFL learners (23 males and 37 females) from Nahal, Nik, Rastak and Noyan English institutes in Isfahan, Iran, whose age range from 16 to 25. None of the participants had the experience of residence in the English speaking countries and none of the participants reported any significant out-of class contact with English native speakers.

Before data collection, an OPT (Oxford Placement Test) was administered as a standardized measure to check the homogeneity of subjects in terms of their language proficiency. This test was consisted of 60 vocabulary and grammatical items containing multiple choice, completion and cloze test questions and a writing section. Having obtained the proficiency test results, the researchers chose those participants whose score range fell one standard deviation above and below the mean (i.e.mean \pm 1). Accordingly, 44 intermediate EFL learners (17 males and 27 females) were selected to participate in this study.

\subsection{Materials and Instruments}

The following instruments were used in conducting this study:

Oxford Placement Test (OPT): This test was administered as a standardized measure to check the homogeneity of subjects in terms of their language proficiency. This test consists of 60 vocabulary and grammatical items containing multiple choice, completion and cloze test questions and a writing section. Having obtained the proficiency test results, the researchers decided to choose those participants whose score range fell one standard deviation above and below the mean (i.e.mean \pm 1 ).

Two Oral Tasks: two oral tasks were used. One of these tasks was familiar (events in Iran) for the learners and the other one was unfamiliar (events in China) each of which was done two times. Four pictures were presented through PowerPoint for each task.

Interview Questions: A Stimulated recall interview was conducted with the participants immediately after the first and the second time performances to capture their inner thoughts about speech production and affective responses to content familiarity and task repetition. These questions were: 1) How did you feel about the task and your performance? ; 2) In your own opinion, which tasks did you perform better?; and some follow-up questions based on their answers.

\subsection{Procedures}

After selecting the intermediate participants, they were provided with the two oral tasks. Each participant performed the two tasks with counterbalanced orders in a private meeting room. Each participant performed the two tasks by the use of some pictures. Their performances were done in a class for three to five audiences and an interlocutor (the researcher). To create a communicative environment, the interlocutor provided responsive words (e.g. hmm, okay). After the participants 
performed the first tasks, they repeated the two tasks to the same interlocutor after three days. The oral performances were audio-recorded for further analysis.

After the participants' first and second time performances, a stimulated recall interview was conducted with all the selected participants to capture their inner thoughts about speech production and affective responses to content familiarity and task repetition. The researcher played the videos of the participants' performances and prompted them to share their inner thoughts and affective responses when noticing long pauses, repairs, reformulations and other unnatural facial expressions (e.g. laughing) in the videos.

The participants could stop the recordings when they wished. The questions asked in each interview varied, as they depended on special or interesting observations in the videotaped oral performances, but two questions were frequently asked as prompts. These questions were, 'what were you thinking about when you (paused)?' and How did you feel about the task and your performance?' Follow-up questions, such as, 'Why did you think so?' The interviews were conducted in the participants' L1, Persian, to avoid linguistic difficulties that they might have encountered if reporting in their L2.

\section{Results}

\subsection{The First Research Question}

As it was stated above, the first research question of the study was "Does content familiarity affects EFL learners' engagement in L2 oral performance?" This research question clearly wants to find out that whether content familiarity of a task can influence the learners' engagement in L2 oral performance. To find the answer of this question, paired-samples T-test was conducted to compare the performances of the participants in familiar and unfamiliar tasks. As it was mentioned before, just the first performances were considered. Table 4.1 shows mean scores, standard deviations (SD) and $p$ values of the behavioral and cognitive engagement indicators for the two tasks.

Table 4.1.

Descriptive Statistics and Paired samples T-test Results of the First performances of the Familiar and Unfamiliar Task

\begin{tabular}{|c|c|c|c|c|c|c|c|c|}
\hline \multirow[t]{2}{*}{ Task/Conditions } & \multirow[t]{2}{*}{$\mathbf{n}$} & Word Count & \multicolumn{2}{|c|}{ Time on tasks } & \multicolumn{2}{|c|}{ Self-repairs } & \multicolumn{2}{|c|}{$\begin{array}{l}\text { Elaborative } \\
\text { clauses }\end{array}$} \\
\hline & & $\begin{array}{l}\text { Mean } \\
(\mathrm{SD})\end{array}$ & $\begin{array}{l}\text { Mean } \\
(\mathrm{SD})\end{array}$ & $\mathrm{p}$ & $\begin{array}{l}\text { Mean } \\
(\mathrm{SD})\end{array}$ & $\mathrm{p}$ & $\begin{array}{l}\text { Mean } \\
(\mathrm{SD})\end{array}$ & $\mathrm{p}$ \\
\hline $\begin{array}{l}\text { Events } \\
1 \text { (Familiar task) }\end{array}$ & 30 & $\begin{array}{ll}133 & .000 \\
(21.43) & \\
\end{array}$ & $\begin{array}{l}5.50 \\
(1.16) \\
\end{array}$ & .06 & $\begin{array}{l}1.70 \\
(1.29) \\
\end{array}$ & .000 & $\begin{array}{l}4.90 \\
(1.47) \\
\end{array}$ & .000 \\
\hline $\begin{array}{l}\text { Events } \\
1 \\
\text { (Unfamiliar task) }\end{array}$ & 30 & $\begin{array}{ll}93.66 & .000 \\
(12.72) & \end{array}$ & $\begin{array}{l}6.63 \\
(1.88)\end{array}$ & .06 & $\begin{array}{l}3.80 \\
(1.88)\end{array}$ & .000 & $\begin{array}{l}1.53 \\
(1.13)\end{array}$ & .000 \\
\hline
\end{tabular}

On the column of Word Count, the mean score of the familiar task $(\mathrm{M}=133)$ is more than the unfamiliar task $(M=93.66)$. It is indicated that the learners used more words in the task of Events in Iran, since the content was familiar to them. Also, the $\mathrm{p}$ value shows that this difference is significant (.05>.000). In the next column, we can see that the participants spend more time on the unfamiliar task $(\mathrm{M}=6.63)$ than the familiar one $(\mathrm{M}=5.50)$. But this difference is not significant since the $\mathrm{p}$ value is greater than $.05(\mathrm{p}=.06)$.

On the Self repairs column the mean score of the task Events in Iran is 1.70, while the mean score of the task Events in China is 3.80. It shows that the participants corrects themselves words more in the unfamiliar task. The $\mathrm{p}$ value shows that this difference is significant since $.05>.000$. Finally, in the last column named as Elaborative clause, them mean score of the familiar task is higher $(\mathrm{M}=4.90)$ than unfamiliar one $(\mathrm{M}=1.53)$. This is to say that the participants used more questions, arguments or phrases 
demonstrating their intentions to expand their semantic content, reasoning or exemplification. The difference is significant since the $\mathrm{p}$ value is less than the alpha level $(.05>.000)$.

As illustrated in the above tables, it could be concluded that the content familiarity of a task can affect the learners' engagement in L2 oral performance. The learners showed more engagement in familiar task than the unfamiliar one.

\subsection{The Second Research Question}

As it was mentioned before, the second research question of the study was "Does performing tasks repetition affect EFL learners' engagement in L2 oral performance?” More clearly, the second research question of the study intended to find out whether performing a task for the second time can improve learners' engagement in L2 oral performance. To come up with an answer to this question, the first and second performances of the participants on the two topics were compared via paired-samples T-test based on the indicators of behavioral and cognitive engagement. Table 4.2 shows the mean scores, standard deviations (SD) and $\mathrm{p}$ values of the behavioral and cognitive engagement indicators for the four tasks and the two performances of each.

Table 4.2.

Descriptive Statistics and Paired Samples T-test Results the two performances of the Familiar Task

\begin{tabular}{|c|c|c|c|c|c|c|c|c|c|}
\hline \multirow[t]{2}{*}{ Task/Conditions } & \multirow[t]{2}{*}{$\mathbf{n}$} & \multicolumn{2}{|c|}{ Word Count } & \multicolumn{2}{|c|}{ Time on tasks } & \multicolumn{2}{|c|}{ Self-repairs } & \multicolumn{2}{|c|}{$\begin{array}{l}\text { Elaborative } \\
\text { clauses }\end{array}$} \\
\hline & & $\begin{array}{l}\text { Mean } \\
(\mathrm{SD})\end{array}$ & $\mathrm{p}$ & $\begin{array}{l}\text { Mean } \\
(\mathrm{SD})\end{array}$ & $\mathrm{p}$ & $\begin{array}{l}\text { Mean } \\
(\mathrm{SD})\end{array}$ & $\mathrm{p}$ & $\begin{array}{l}\text { Mean } \\
(\mathrm{SD})\end{array}$ & $\mathrm{p}$ \\
\hline Events in Iran 1 & 30 & $\begin{array}{l}133 \\
(21.43)\end{array}$ & .000 & $\begin{array}{l}5.50 \\
(1.16) \\
\end{array}$ & .000 & $\begin{array}{l}1.70 \\
(1.29)\end{array}$ & .02 & $\begin{array}{l}4.90 \\
(1.47) \\
\end{array}$ & .000 \\
\hline Events in Iran 2 & 30 & $\begin{array}{l}156 \\
(18)\end{array}$ & .000 & $\begin{array}{l}7.06 \\
(1.48)\end{array}$ & .000 & $\begin{array}{l}1.03 \\
(.66)\end{array}$ & .02 & $\begin{array}{l}5.80 \\
(1.24)\end{array}$ & .000 \\
\hline
\end{tabular}

In the above table, the indicator of Word count owns higher mean score in the second performance $(M=156)$ of the Events in Iran task than the first performance $(M=133)$. This result indicated that when the task is repeated the participants use more words than in their first performance. The difference in word count between the two performances is significant since .05>.000. On the column of Time on task, we can see that the participants spent more time on the second performance $(M=7.06)$ of the task. This is to say that when the task is repeated, the participants want to improve their first performances and compensate the lacks, thus it takes more time. The difference is significant because the $\mathrm{p}$ value is less than .05 (05>.000). As the Self-Repair column indicates, the participants self-corrected their words more in their first performance $(M=1.70)$ than the second one $(M=1.03)$. This result shows that participants were more comfortable when performing for the second time and they did less self-repair strategies. To see if the difference is significant between the two performances, one should check the $\mathrm{p}$ value. In this section the $p$ value is less than the alpha level, so it's significant $(05>.02)$. Finally, in the last column, the indicator of Elaborative clause shows high mean score in the second performance $(M=5.80)$ than the first performance $(\mathrm{M}=4.90)$. The difference is significant since $.05>.000$.

Based on the illustration of the Table 4.2, the mean scores in Word count, Self-repairs and Elaborative clause indicators were higher than the mean scores in the first performance. Thus we can conclude that the participants engage more in the second performance of the task than in the first one. The Table 4.3 shows the differences between the first and second performances of the unfamiliar task. 
Table 4.3.

Descriptive Statistics and Paired Samples T-test Results the two performances of the Unfamiliar Task

\begin{tabular}{|c|c|c|c|c|c|c|c|c|c|}
\hline \multirow[t]{2}{*}{ Task/Conditions } & \multirow[t]{2}{*}{$\mathbf{N}$} & \multicolumn{2}{|c|}{ Word Count } & \multicolumn{2}{|c|}{ Time on tasks } & \multicolumn{2}{|c|}{ Self-repairs } & \multicolumn{2}{|c|}{$\begin{array}{l}\text { Elaborative } \\
\text { clauses }\end{array}$} \\
\hline & & $\begin{array}{l}\text { Mean } \\
(\mathrm{SD})\end{array}$ & $\mathrm{p}$ & $\begin{array}{l}\text { Mean } \\
(\mathrm{SD})\end{array}$ & & $\begin{array}{l}\text { Mean } \\
(\mathrm{SD})\end{array}$ & & $\begin{array}{l}\text { Mean } \\
(\mathrm{SD})\end{array}$ & $\mathrm{p}$ \\
\hline Events in 1 & 30 & $\begin{array}{l}66.33 \\
(17.11) \\
\end{array}$ & .000 & $\begin{array}{l}6.63 \\
(1.88) \\
\end{array}$ & .000 & $\begin{array}{l}3.80 \\
(1.88) \\
\end{array}$ & .000 & $\begin{array}{l}1.53 \\
(1.13) \\
\end{array}$ & .000 \\
\hline Events in 2 & 30 & $\begin{array}{l}93.66 \\
(12.72)\end{array}$ & .000 & $\begin{array}{l}8.13 \\
(1.10)\end{array}$ & .000 & $\begin{array}{l}1.56 \\
(1.16)\end{array}$ & .000 & $\begin{array}{l}3.16 \\
(1.36)\end{array}$ & ‘.000 \\
\hline
\end{tabular}

In table 4.3, the indicator of Word count has higher mean score in the second performance $(M=93.66)$ of the Events in Iran task than the first performance $(M=66.33)$. This result indicated that when the task is repeated the participants use more words than in their first performance. The difference in word count between the two performances is significant since .05>.000. On the column of Time on task, we can see that the participants spent more time on the second performance $(M=8.13)$ of the task. This is to say that when the task is repeated, the participants want to improve their first performances and compensate the lacks, thus it takes more time. The difference is significant because the $\mathrm{p}$ value is less than .05 (05>.000). As the Self-Repair column indicates, the participants self-corrected their words more in their first performance $(\mathrm{M}=3.80)$ than the second one $(\mathrm{M}=1.56)$. This result shows that participants were more comfortable when performing for the second time and they did less self-repair strategies. To see if the difference is significant between the two performances, one should check the $p$ value. In this section the $\mathrm{p}$ value is less than the alpha level, so it's significant (05>.000). Finally, in the last column, the indicator of Elaborative clause shows high mean score in the second performance $(\mathrm{M}=3.16)$ than the first performance $(\mathrm{M}=1.53)$. The difference is significant since $.05>.000$.

Based on Table 4.2, the mean scores in Word count, Self-repairs and Elaborative clause indicators were higher than the mean scores in the first performance. Thus, like the familiar task, we can conclude that the participants engage more in the second performance of the unfamiliar task than in the first one. Therefore, the repetition of the task helps the participants to engage more in the second tasks.

\subsection{The Results of the Interview}

As stated before in chapter three, After the participants' first and second time performances, a stimulated recall interview was conducted with all the selected participants to capture their inner thoughts about speech production and affective responses to content familiarity and task repetition. The interview questions are as follow:

1) How did you feel about the task and your performance?

2) In your own opinion, which tasks did you perform better in?

A category of contents were derived from the participants' answers to the interview questions. The numbers and percentages of participants who answered to the interview questions are reported individually for each task, based on a content analysis.

\subsubsection{Results of the Interview Questions for the Familiar Task}

To see the results of the interview questions for the familiar task we should take a look at the Table 4.4 and 4.5 . 
Table 4.4.

The Results of the First Interview Question for the Familiar Task

\begin{tabular}{|l|l|l|l|l|l|l|}
\hline & Fun & Boring & Unconfident & Nervous & Confident & Challenging \\
\hline $\mathbf{1}^{\text {st }}$ performance & 15 & 0 & 10 & 7 & 8 & 11 \\
& $68 \%$ & $0 \%$ & $45 \%$ & $31 \%$ & $36 \%$ & $50 \%$ \\
\hline $2^{\text {nd }}$ performance & 13 & 10 & 0 & 2 & 19 & 3 \\
& $59 \%$ & $45 \%$ & $0 \%$ & $9 \%$ & $86 \%$ & $13 \%$ \\
\hline
\end{tabular}

From the output shown above, we know that there are 22 interviewees in the sample. In the first performance the positive answer of Fun and the Negative answer of Unconfident and Nervous got high percentages to the first interview question. On the other hand, in the second performance, the positive answer of Confident, and negative answers of Boring and Challenging got high percentages to the first interview question.

Table 4.5.

The Results of the Second Interview Question for the Familiar Task

\begin{tabular}{|l|l|}
\hline $\mathbf{1}^{\text {st }}$ performance & $\mathbf{4}$ \\
& $\mathbf{1 8 \%}$ \\
\hline $\mathbf{2}^{\text {nd }}$ performance & 18 \\
& $81 \%$ \\
\hline
\end{tabular}

Table 4.5 shows that $18 \%$ percent of the participants think that they perform better in their first performance and $81 \%$ of them believe that they perform better in the $2^{\text {nd }}$ performance of the familiar task.

\subsubsection{Results of the Interview Questions for the Unfamiliar Task}

To see the results of the interview questions for the unfamiliar task we should take a look at the table 4.6 and 4.7 .

Table 4.6.

The Results of the First Interview Question for the Unfamiliar Task

\begin{tabular}{|l|l|l|l|l|l|l|}
\hline & Fun & Boring & Unconfident & Nervous & Confident & Challenging \\
\hline $1^{\text {st }}$ performance & 5 & 4 & 20 & 18 & 0 & 21 \\
& $22 \%$ & $18 \%$ & $90 \%$ & $81 \%$ & $0 \%$ & $95 \%$ \\
\hline $2^{\text {nd }}$ performance & 16 & 0 & 7 & 12 & 10 & 17 \\
& $72 \%$ & $\%$ & $31 \%$ & $54 \%$ & $45 \%$ & $77 \%$ \\
\hline
\end{tabular}

Table 4.6 shows that in the first performance the positive answer of Fun and Confident got low percentage and all the Negative answers got high percentages to the first interview question. On the other hand, in the second performance, the positive answers of Fun and Confident were increased and the percentages of negative answers of Boring, Unconfident, nervous and challenging were decreased.

Table 4.7.

The Results of the Second Interview Question for the Unfamiliar Task

\begin{tabular}{|l|l|}
\hline $\mathbf{1}^{\text {st }}$ performance & $\mathbf{0}$ \\
& $\mathbf{0 \%}$ \\
\hline $\mathbf{2}^{\text {nd }}$ performance & 22 \\
& $100 \%$ \\
\hline
\end{tabular}




\subsection{The Third Research Question}

As might be recalled, the second research question of the study was "What are the potential interaction effects between content familiarity and task-repetition on EFL learners' engagement in L2 oral performance?"

The potential interaction effect between content familiarity and task repetition can been seen in Table 4.1, 4.2 and 4.3 where the effect of familiarity seems to change between the first and second performances in the number of all four indicators. Significant differences were found between the familiar and unfamiliar topics in the first performance, and in the repeated performances. A potential interaction effect was spotted between content familiarity and task repetition in terms of the four indicators. The decrease of self-repairs in task repetition was more obvious for the both familiar and unfamiliar topics in their second performances.

Moreover, in the stimulated recall interview 10 participants (45\%) indicated that they felt bored at repeating the familiar tasks but they tried to perform better than the first time. on the other hand, they show their motivation in performing the unfamiliar task for the second time.

\section{Discussion and Conclusion}

This study investigated the effects of content familiarity and task repetition on Iranian EFL learners' engagement in L2 oral performance. As far as the first research question was concerned," Does content familiarity affects EFL learners' engagement in L2 oral performance?" the present study found that, found that the participants engage more in familiar task than in unfamiliar task in their first performance. This result indicates that content familiarity of a task can affect the learners' engagement in L2 oral performance. Therefore, it can be concluded that when the content of a speaking task is familiar for the learners, they can use more words, more elaborative tasks in a shorter time and make less errors to use self-repairs than in unfamiliar task. In another word, the learners' engagement is more dominant in familiar tasks.

According to the schema theory (Bartlet, 1932), the background knowledge is represented in a way that facilitates the use of the knowledge in particular ways. The familiar topics are kept in background knowledge. Thus, when one needs to produce language on a topic, the kept knowledge in schema interfere with the interpretation of new information (Carrell, 1991), and the production becomes easier.

The findings of our study are in line with some studies. Gass and Varonis (1984) found that topic familiarity affected not only participants' comprehension, but also the amount of negotiation, with more comprehension and greater negotiation achieved in more familiar tasks. In another study by Phung (2017), it is found that L2 learners had negative affective responses to tasks with unfamiliar topics, whereas they felt more positive towards tasks with familiar topics. Finally, Yi Lu \& Qui (2017) found that content familiarity can have an impact on learners' engagement.

As for the second research question," Does tasks repetitions affect EFL learners' engagement in L2 oral performance?" it was found that the participants, in their second performance, gained higher mean scores on word count, time on task and elaborative task, and lower mean score in self-repairs compared to their first performance of the familiar and unfamiliar tasks. We can conclude that the participants engage more in the second oral performances of the familiar and unfamiliar task than in the first ones. Therefore, the repetition of the task helps the participants to engage more in the second tasks.

It is indicated from this result that when a task is repeated for the second time, the participants' background knowledge and experience is improved from the first performance. Therefore, it can help them to perform better and compensate the lacks of the first performance.

The findings of our study are different from the finding of Qui \& Yi Lu (2016) who explored the influence of content familiarity and task repetition on English as a foreign language (EFL) learners' engagement in oral performance. They found that task repetition can negatively influenced behavioral and cognitive engagement, although the participants felt more relaxed and confident. Additionally, the participants were more motivated to repeat unfamiliar topics. But like our findings, they demonstrated 
more noticeable declines in their frequency of self-repair (an indicator of cognitive engagement) for these topics. In another example, Phung (2017) found that L2 learners had negative affective responses to tasks with unfamiliar topics

Finally for the third research question, "What are the potential interaction effects between content familiarity and task-repetition on EFL learners' engagement in L2 oral performance?” It is indicated from the obtained results that a potential interaction effect was spotted between content familiarity and task repetition in terms of the four indicators.

In terms of cognitive engagement, more elaborative clauses were produced for the familiar topic. The decrease of self-repairs in task repetition was more obvious for the both familiar and unfamiliar topics in their second performances. This may imply that the familiar topic more effectively engaged learners in reasoning and exemplification, whereas the unfamiliar topic might have more effectively engaged them in monitoring (Wolters \& Taylor, 2012).

In terms of behavioral engagement there were significant differences in word count and time on time in familiar and unfamiliar topics' first and second performance. And finally, in terms of emotional engagement, however, participants had some positive and negative affective responses for both performances of the familiar and unfamiliar topics in different ways. Such findings are consistent with those of Phung (this issue), who found that prior knowledge (familiar/unfamiliar topics) affected L2 learners' emotional engagement, as they perceived the familiar topics to be simpler and preferable.

Therefore, the following results were reached upon the completion of the experiment: (a) the content familiarity of a task can affect the learners' engagement in L2 oral performance; (b) the repetition of the task helps the participants to engage more in the second tasks; and (c) a potential interaction effect was spotted between content familiarity and task repetition in terms of the four indicators.

\section{Appendix-A \\ Events in Iran (Newrooz)}

$\checkmark$ Look at the series of pictures and explain the event.
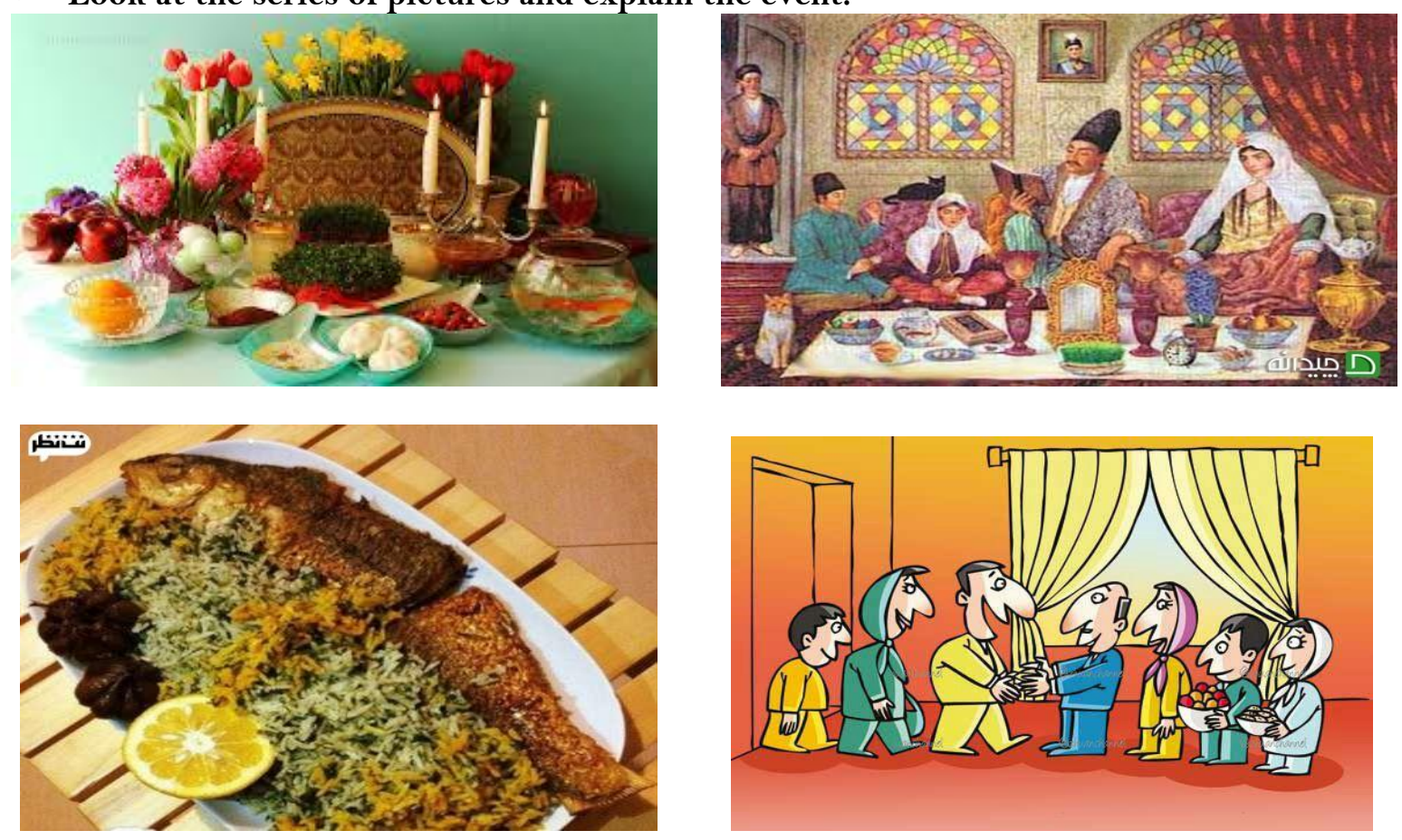

Contemporary Research in Education and English Language Teaching

ISSN: 2641-O230

Vol. 1, No.4, pp. 45-56, 2019

DOI: $10.33094 / 26410230.2019 .14 .45 .56$

(C) 2019 by the authors; licensee Learning Gate 


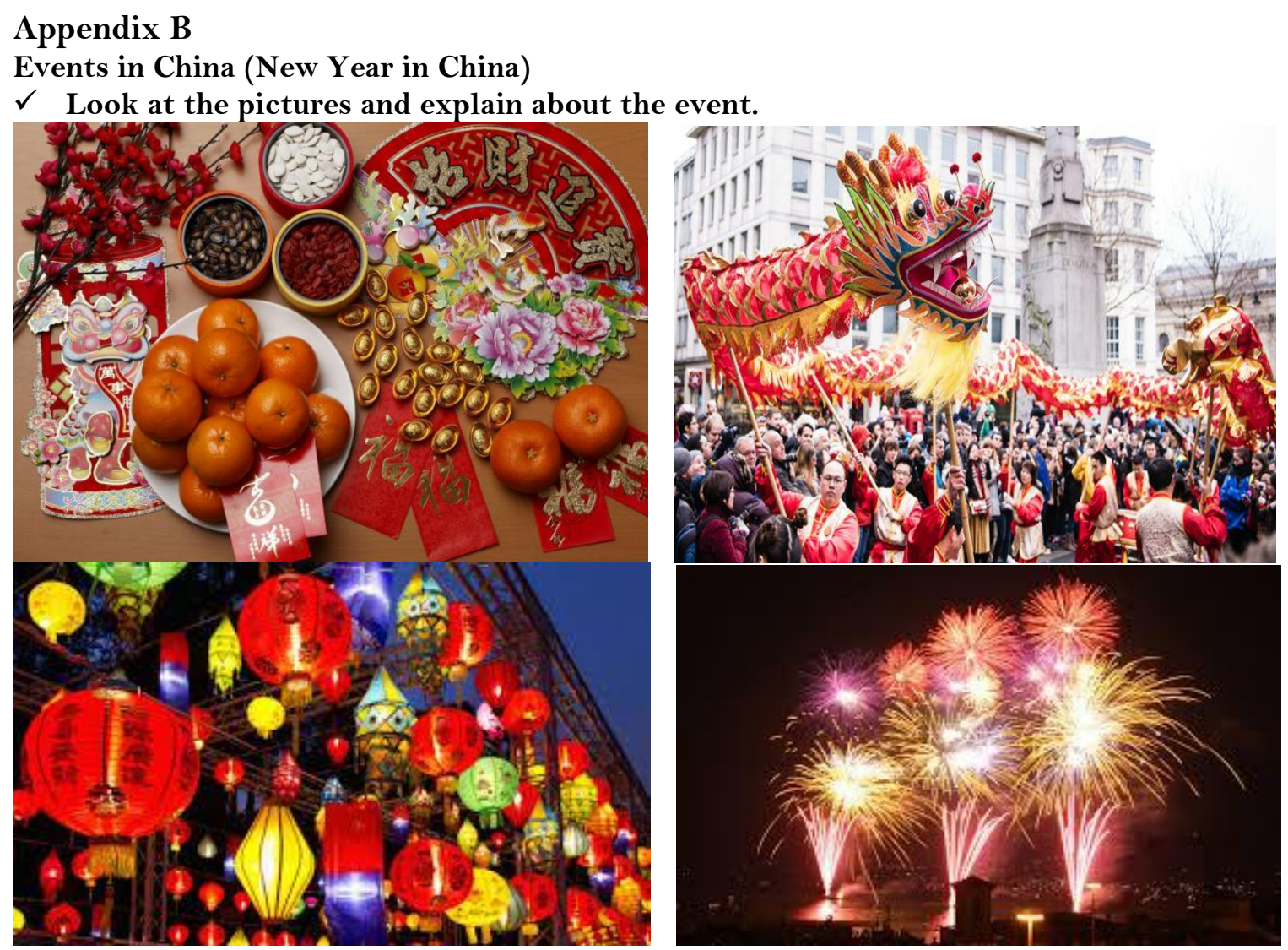

\section{References}

Ahmadian, M. J., \& Tavakoli, M. (2011). The effects of simultaneous use of careful online planning and task repetition on accuracy, complexity, and fluency in EFL learners' oral production. Language Teaching Research, 15(1), 35-59.

Baralt, M., Gurzynski-Weiss, L., \& Kim, Y. (2016). Engagement with the language: How examining learners' affective and social engagement explains successful learner-generated attention to form. Peer interaction and second language learning: Pedagogical potential and research agenda, 209240.

Barnes, T., Powell, E., Chaffin, A., \& Lipford, H. (2008). Game2Learn: Improving the engagement and motivation of CS1 students. ACM GDCSE, 8.

Birjandi, P., \& Ahangari, S. (2008). Effects of task repetition on the fluency, complexity and accuracy of Iranian EFL learners' oral discourse. Asian EFL Journal, 10(3), 28-52.

Bozorgian, H., \& Kanani, S. M. (2017). Task repetition on accuracy and fluency: efl learners'speaking skill. International Journal of English Language and Literature Studies, 6(2), 42-53.

Bygate, M. (1996). Effects of task repetition: appraising learners' performances on tasks. Challenge and change in language teaching, 136-146.

Bygate, M. (2001). Speaking. The Cambridge Guide to Teaching English to Speakers of Other Languages.

Bygate, M., \& Samuda, V. (2005). Integrative planning through the use of task repetition.

Carrell, P. L. (1987). Content and formal schemata in ESL reading. TESOL quarterly, 21(3), 461-481. 
Carrell, P. L. (1991). Second language reading: Reading ability or language proficiency?. Applied linguistics, 12(2), 159-179.

Christenson, S. L., Reschly, A. L., \& Wylie, C. (Eds.). (2012). Handbook of research on student engagement. Springer Science \& Business Media.

Ellis, R. (2003). Task-based language learning and teaching. Oxford University Press.

Ellis, R. (2009). Task-based language teaching: Sorting out the misunderstandings. International Journal of Applied Linguistics, 19(3), 221-246.

Ellis, R. (2009). The differential effects of three types of task planning on the fluency, complexity, and accuracy in L2 oral production. Applied linguistics, 30(4), 474-509.

Ellis, R. (2010). Epilogue: A framework for investigating oral and written corrective feedback. Studies in Second Language Acquisition, 32(2), 335-349.

Foster, P., \& Skehan, P. (1996). The influence of planning and task type on second language performance. Studies in Second language acquisition, 18(3), 299-323.

Gass, S., \& Varonis, E. M. (1984). The effect of familiarity on the comprehensibility of nonnative speech. Language learning, 34(1), 65-87.

Gilakjani, A. P., \& Ahmadi, S. M. (2011). The Relationship between L2 Reading Comprehensionand Schema Theory: A Matter of Text Familiarity. International Journal of Information and Education Technology, 1(2), 142.

Lambert, C., Kormos, J., \& Minn, D. (2017). Task repetition and second language speech processing. Studies in Second Language Acquisition, 39(1), 167-196.

Leaver, B. L., \& Willis, J. R. (Eds.). (2004). Task-based instruction in foreign language education: Practices and programs. Georgetown University Press.

Leeser, M. J. (2007). Learner-based factors in L2 reading comprehension and processing grammatical form: Topic familiarity and working memory. Language learning, 57(2), 229-270.

Mercer, N., \& Dawes, L. (2008). The value of exploratory talk. Exploring talk in school, 55-71.

Philp, J., \& Duchesne, S. (2016). Exploring engagement in tasks in the language classroom. Annual Review of Applied Linguistics, 36, 50-72.

Phung, L. (2017). Task preference, affective response, and engagement in L2 use in a US university context. Language Teaching Research, 21(6), 751-766.

Qiu, X., \& Lo, Y. Y. (2017). Content familiarity, task repetition and Chinese EFL learners' engagement in second language use. Language Teaching Research, 21(6), 681-698.

Rahimpour, M., \& Hazar, F. (2007). Topic familiarity effect on accuracy, complexity, and fluency of L2 oral output. The Journal of AsiaTEFL, 4(4), 191-211.

Reeve, J. (2012). A self-determination theory perspective on student engagement. In Handbook of research on student engagement (pp. 149-172). Springer, Boston, MA.

Robinson, P. (2007). Task complexity, theory of mind, and intentional reasoning: Effects on L2 speech production, interaction, uptake and perceptions of task difficulty. IRAL-International Review of Applied Linguistics in Language Teaching, 45(3), 193-213.

SCHMIDT-RINEHART, B. C. (1994). The effects of topic familiarity on second language listening comprehension. The modern language journal, 78(2), 179-189.

Wolters, C. A., \& Taylor, D. J. (2012). A self-regulated learning perspective on student engagement. In Handbook of research on student engagement (pp. 635-651). Springer, Boston, MA.

Yazdanpanah, K. (2007). The effect of background knowledge and reading comprehension test items on male and female performance. The reading matrix, $7(2)$. 